\title{
Empirical Analysis of Price Fluctuation and Characteristics of Specialty Agriculture Crops - Under the Investigation on Pepper
}

\author{
Yan Jianwei \\ College of Economics and Management, Zhoukou Development Research Centre, Zhoukou Normal University, Zhoukou, China \\ Email address: \\ 1540513949@qq.com
}

\section{To cite this article:}

Yan Jianwei. Empirical Analysis of Price Fluctuation and Characteristics of Specialty Agriculture Crops - Under the Investigationon Pepper. Science Discovery. Vol. 4, No. 2, 2016, pp. 86-93. doi: 10.11648/j.sd.20160402.16

Received: December 8, 2015; Accepted: March 23, 2016; Published: May 18, 2016

\begin{abstract}
Careen characteristic of modern agriculture crops, it is an important part of the modernization of agriculture. Pepper is one kind of important and special agricultural crop, price fluctuation will have an directly affection on increase of farmers income, thereby affecting the development of pepper industry. Based on the analysis of current situation and the causes of price fluctuation on pepper, making use of Variety of statistical measurement methods of Price Fluctuation and Characteristics of Chinese Pepper nearly eight years. The results show: Price volatility of pepper is of diversity. Price fluctuation of pepper showed a high frequency, low resistance, big discrete, slightly flat and moderate right-skewed distribution of morphological characteristics; Simultaneously Price fluctuation of pepper also has a seasonal, irregular, cyclical trend, cyclical, non-agglomeration features. Accordingly, the article suggest the government should Combine with price changes reasons of pepper, grasping the variation characteristics of pepper from all aspects, do the following work: macro statistical information, the main producing areas of support, information platform construction, perfection futures options and so on.
\end{abstract}

Keywords: Economic Crops, Price Fluctuation, Seasonal Adjustment, Accumulative Effect

\section{特色农业经济作物价格波动特征的实证分析--以辣椒作物为例}

\section{间建伟}

周口师范学院经济与管理学院, 周口发展研究中心, 周口, 中国

\section{邮箱}

1540513949@qq. com

摘要: 小宗特色农业经济作物的现代化, 是农业现代化的重要组成部分。特色经济作物辣椒作为中国重点特色农业 经济作物之一，其价格波动将直接影响种植户收入的增加，影响辣椒产业的发展，进而影响小宗特色农业经济作物 的现代化进程。本文首先分析了中国辣椒价格的现状及波动原因，然后截取中国2008年5月至2016年3月辣椒价格波 动的时间序列数据, 采用多种计量统计方法对价格波动特征进行实证分析, 结果表明: 辣椒价格波动具有多样性特 征; 辣椒价格变化具有高发性、低水平运行性、较大偏差性、轻微偏态和中等右偏峰态分布特征; 同时, 辣椒价格 波动展现出季节性、不规则性、趋势循环性、周期性、非集簇性等特征。据此，建议政府应密切关注特色经济作物 价格变化, 全面把握国际产业价格变化的规律特征, 做好产业历史数据统计, 加强重要产区扶持, 完善市场平台建 设、健全期货期权机制等。

关键词：经济作物, 价格波动, 季节调整, 集簇效应 


\section{1. 引言}

农业现代化不仅是大宗粮食作物要实现现代化, 也是 小宗特色农业经济作物的现代化。辣椒是世界上具有良好 发展前景的经济作物之一, 在中国小宗特色农业经济作物 实现现代化过程中, 占有重要的地位。据FAO统计显示, 2013年中国辣椒种植面积约 2300 万亩, 其中干辣椒年产量 近 30 万吨, 是世界上第一辣椒种植和消费大国, 也是辣椒 出口最多的国家。目前, 辣椒产业已成为中国许多省市的 主要经济支柱产业, 其中种植面积超过100万亩的省份就 有8个，其在增加农民就业、增加农户收入、促进地方农 村经济发展方面具有重大的现实意义。但近年来, 辣椒市 场价格波动频繁且幅度较大, 严重地影响了辣椒种植的稳 定, 挫伤了农户的积极性, 制约了辣椒产业的发展。因此, 深入研究辣椒市场价格波动的特征与规律, 对加强农户生 产决策与政府宏观调控，促进辣椒产业发展具有重大积极 作用。

国际上有关大宗粮食、蔬菜类、肉禽蛋奶类等农产品 价格波动的研究成果较多并且方法比较成熟。例如中国学 者朱信凯（2012）、宋雨河（2013）、李正辉（2013）、 夏冰（2015）、周金城（2014）等对农产品价格波动特征 进行了研究 [1]-[5]; 庄岩 (2013) 、付莲莲 (2014)、 文春玲（2014）、姜雅莉（2013）、蒋兴红（2014）、董 志伟 (2014) 等对影响农产品价格波动的因素进行了分析 [6]-[12]; 庞贞燕, 刘否（2013）、方燕, 邓洁（2013）、 谢长伟（2013）、董婉璐（2014）等农产品期货市场价格 进行了研究 [13]-[16]。国际学者Nathan P. Hendricks (2015) 、Philip Garcia; Scott H. Irwin (2014)、 Christopher L. Gilber (2014)、Tim Josling; Kym Anderson（2010）等对国际农产品价格波动的原因及期货 模式进行了论证 [27]-[31]。但是对于特色农业经济作物 价格波动的研究还比较少, 尤其是与农民利益密切相关的 辣椒作物价格变化研究几乎很少被涉及。目前, 中国辣椒 价格研究主要集中在两个方面: 一是价格变化的预测研究, 例如韩雯（2008）、张建华（2014）等分别利用ARIMA模
型、小波神经网络智能模型, 对辣椒月度价格进行了预测 [21]-[22]。二是价格变化的原因研究, 例如赵安平 (2014) 等利用VAR模型指出辣椒价格波动受其他蔬菜价格的影响 较大。王永平等 (2011) 对2009年辣椒价格进行了研究, 指出价格波动的本质是供求关系 [23]-[24]。还有一些学 者认为, 马艳青 (2011) 、李晴（2009）等国外游资、投 机炒作等对辣椒价格波动也有较大的影响 [25]-[26]。国 际关于辣椒价格方面的研究, Nathan P. Hendricks (2015)、 Philip Garcia; Scott H. Irwin (2014)、Christopher L. Gilbern（2014）、Céline Bonne（2013）等重点辣椒 价格期货及贸易进行了研究; Dae Sung Kim（2014）、 An-Cheng Huang（2014）等也对辣椒波动进行了简要分析 [32]。相比较而言, 针对中国辣椒价格波动的特征研究几 乎没有被涉及, 而只有掌握了辣椒价格波动的主要特征, 才能更全面、准确地对价格进行预测, 更好、更及时的对 辣椒产业进行调控和指导。本文基于中国辣椒价格波动的 现状与原因分析, 利用中国 2008 年5月-2015年9月共89个 辣椒月度数据, 将经济统计学X12季节调整、BP滤波和 $\mathrm{ARCH}$ 效应分析法等相结合, 对反映辣椒价格数据的集中性、离 散性与波动形态和反映辣椒价格波动的季节性、趋势循环 性、周期性、集簇性与否等特征进行了实证计量分析, 以 全面论证中国辣椒价格波动的特征与规律。

\section{2. 中国辣椒价格波动现状及原因分析}

\section{1. 价格波动的现状}

根据调查统计, 2008年5月至2016年3月中国辣椒价格 波动比较频繁且幅度较大。例如, 国内辣椒产业在 2008 年金融危机中受到较大的影响, 全国各地区一度价格低迷, 但到了2009年后期, 中国（浙江、甘肃、山东、四川、广 州等）多省份辣椒价格持续上涨, 较之 2008 年同期普遍上 涨了 $1 \sim 3$ 倍, 其中个别地区干辣椒的批发价竟然高达 42 元 / 公斤, 继 “蒜你狠”、“姜你军”、“豆你玩”之后, “辣翻天”一度成为最热门的网络术语。

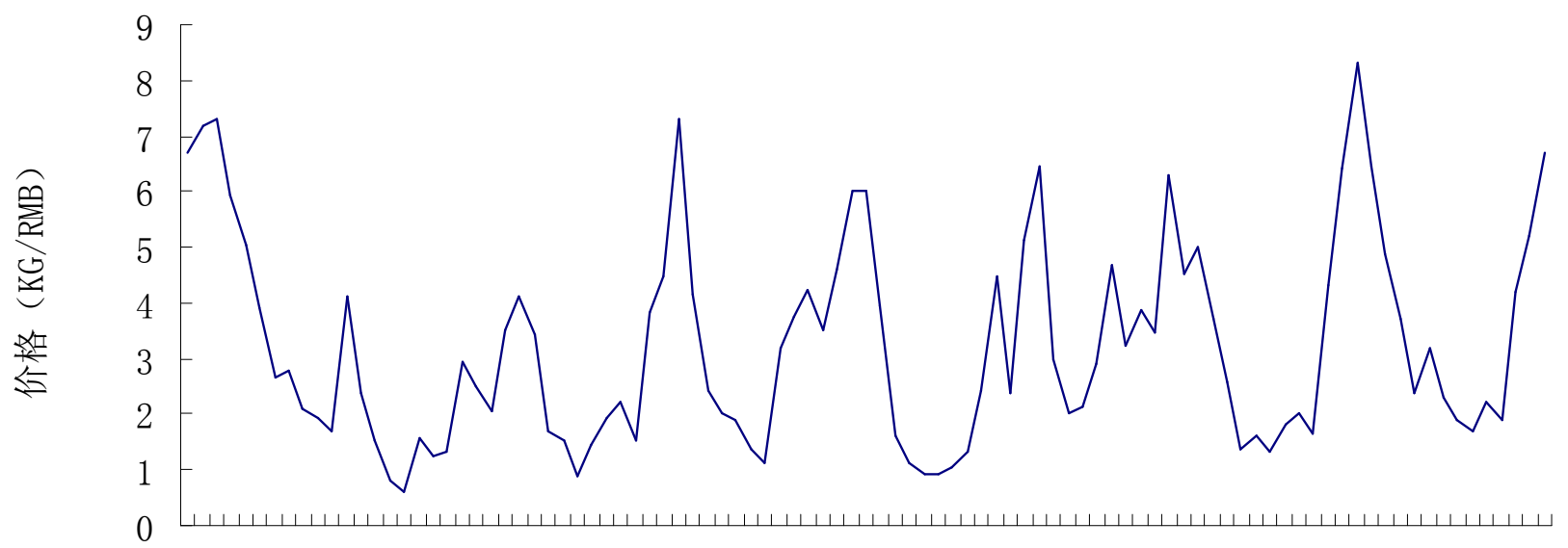

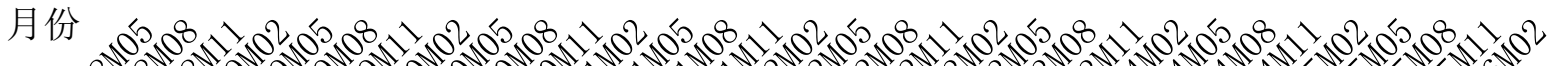

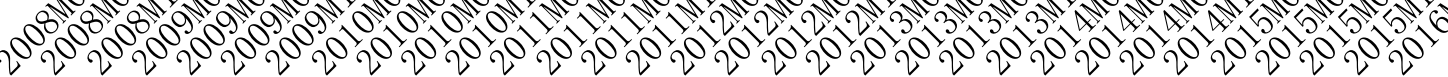

图1 2008年5月-2016年3月中国辣椒价格变化趋势。 
同时, 近 8 年来辣椒月度价格变化中, 根据上图 1 和下 表1所示, 一方面, 共出现约8次连续暴涨暴跌的情况, 最 高价格高达 8.3 元/千克, 最低价格仅为 0.62 元/千克, 远 低于平均价格 3.19 元/千克的水平; 另一方面, 统计显示 价格 1.33 元/千克出现次数较多, 中间位置价格水平为 2.65 元/千克, 说明大部分价格在均值以下的低水平运行。 可见, 中国辣椒市场价格很不稳定, 频繁的价格忽高忽低 的变化, 对辣椒产业的发展非常不利。

表1 2008年5月-2016年3月中国辣椒 95 个月度价格数据特征。

\begin{tabular}{llllll}
\hline 指标 & 平均数 & 众数 & 中位数 & 最小值 & 最大值 \\
\hline 数值 & 3.19 & 1.33 & 2.65 & 0.62 & 8.30 \\
\hline
\end{tabular}

\section{2. 价格波动的原因}

辣椒市场的价格波动, 并不是某一单独因素所引起的, 是受多重因素共同影响所致。综合行业市场调查和文献分

析, 中国辣椒价格变化的原因主要是进出口贸易、国内需 求、生产供给、信息不对称、投机炒作等因素。

\subsection{1. 进出口贸易规模}

辣椒产业是中国特色农业经济作物中的优势产业, 种 植面积、消费规模、出口量均居世界之首。据联合国粮农 组织统计, 中国辣椒年出口量占国内生产总量的 $30 \%$ 以上, 出口量在 10 万吨以上, 价值约 3 亿美元。下图 2 显示, 中国 年辣椒出口量存在较大的波动, 但总体在高水平线运行。 近年来, 韩国、日本、墨西哥、澳大利亚、美国、东南亚 等国家和地区已成为中国辣椒的常年进口国, 仅墨西哥辣 椒就有 $1 / 3$ 是从中国进口的, 日本进口辣椒的 $90 \%$ 来自中国。 同时, 中国年辣椒进口量也在较稳定地逐年增加, 自2009 年以来中国辣椒进口量增加较为迅速, 进口规模近 1 万吨。 另外, 由图3可知, 中国辣椒出口价格与出口量有着很大 的一致性, 可见辣椒的进出口贸易, 是影响辣椒价格的重 要因素之一。

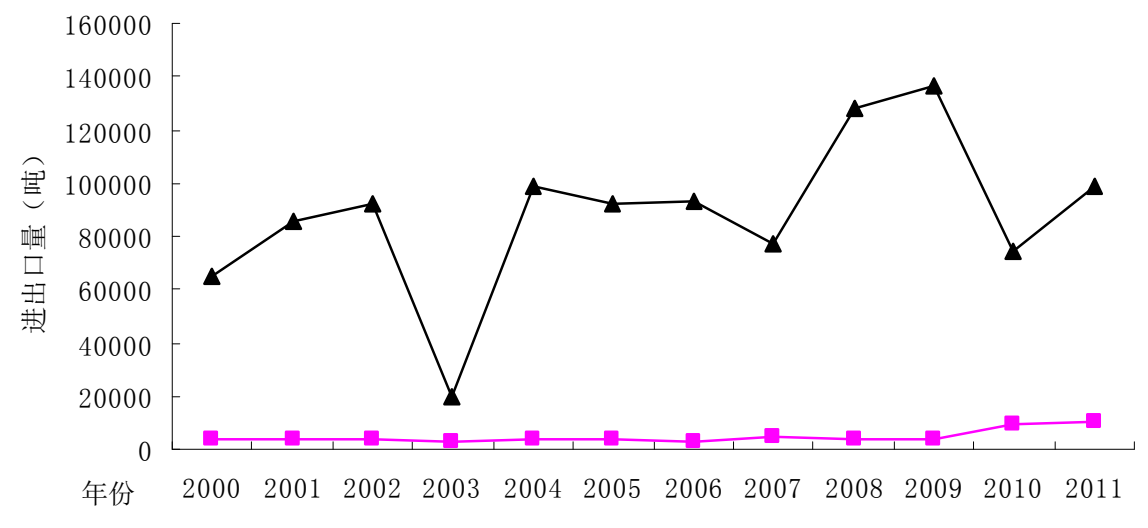

图2 2000年至2012年中国辣椒进出口贸易规模。

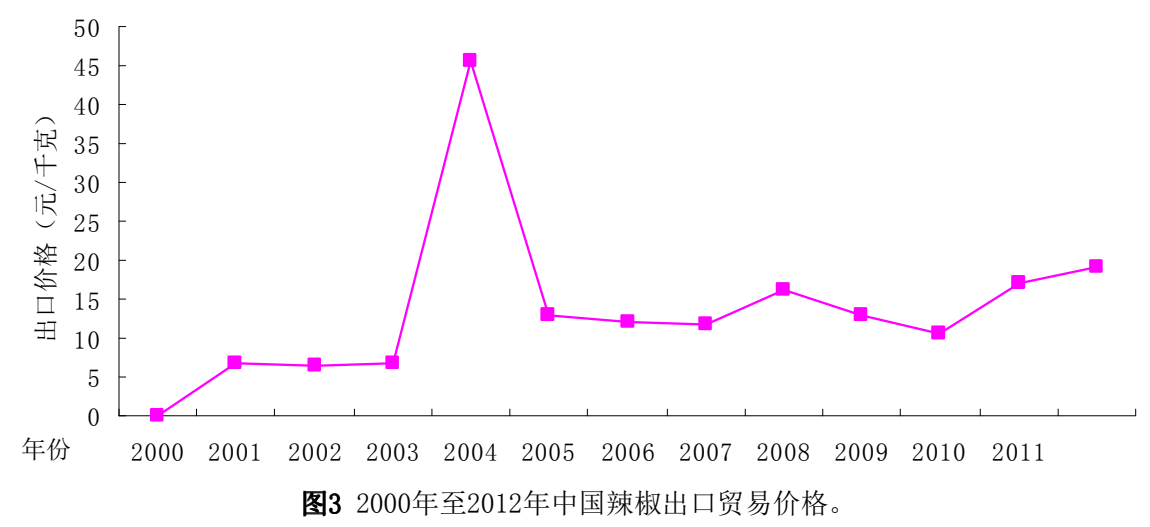

\subsection{2. 市场需求}

辣椒产业的发展离不开稳定且不断扩大的市场需求, 而需求又是支持与稳定辣椒市场价格的重要因素。随着人 们对辣椒食用与开发价值认识的不断提高, 辣椒及其制品 在国际市场上十分走俏, 迅速发展成为全世界消费量最大 的蔬菜之一。例如中国 (湖南、湖北、江西、贵州、四川、 河南及黑龙江等多地居民多喜辣, 流传有 “贵州人不怕辣、 湖南人辣不怕, 四川人怕不辣” 之说。另一方面, 随着辣 椒种植、加工、应用技术的发展, 辣椒已经成为重要的天
然色素、制药原料和其它重要工业原料, 实现产业年产值 270 多亿元。同时辣椒加工企业不断涌现, 规模较大的企业 有200多家, 涌现出不少国际知名的辣椒品牌, 如“老干妈”、 “老干爹” 等, 有力地促进了中国辣椒产业的发展。

\subsection{3. 市场供给}

辣椒生产供给的稳定是保障辣椒市场价格良性变化 的又一重要因素。作为经济作物的同时, 辣椒在中国已发 展成为仅次于大白菜的第 2 大蔬菜作物, 常年种植面积稳 
定在2000万亩以上, 产值和效益雄居蔬菜作物之首, 对于 刺激辣椒产业发展, 稳定辣椒市场价格起了巨大作用。中 国已形成了以贵州、湖南、江西、云南、四川、陕西、河 北、河南、吉林等 16 个省 (区) 的重点辣椒产区，有 160 多 个县域将辣椒作为重要的特色农产品和支柱产业加以发 展。下图4反映出2000-2012年中国辣椒供给处于稳定增长

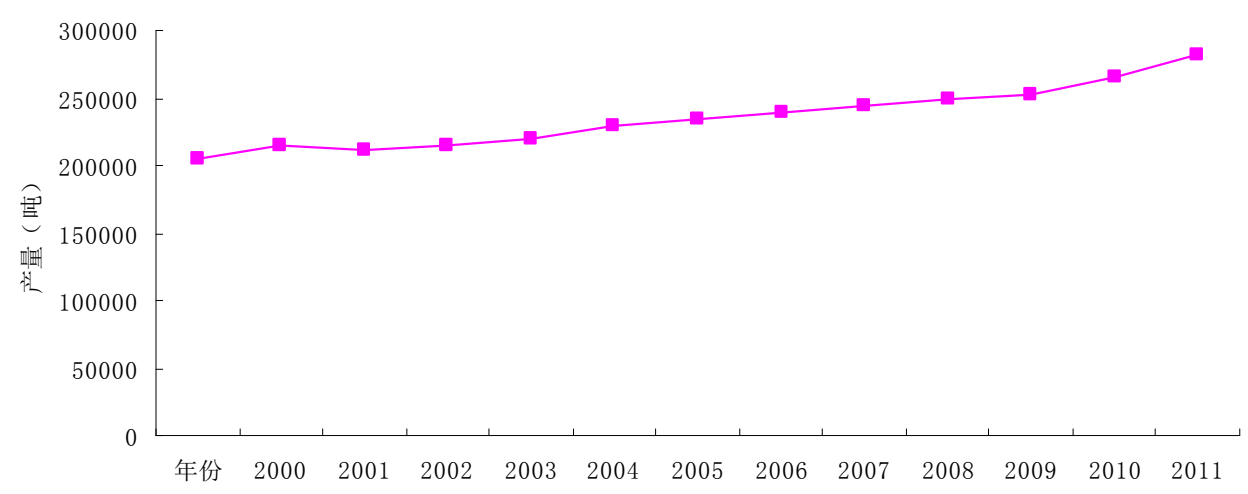

图42000年至2012年中国辣椒市场供给量。

\section{2. 4. 信息不对称与投机行为}

目前中国辣椒价格形成机制并不是完全取决于市场 供求关系, 近年来受资本投机与炒作因素的影响越来越大。 辣椒属于小品种农产品，有限资金的集中投放，就能造成 大面积市场囤积性缺货, 很容易被游资炒作利用。另一方 面, 加上市场上供求主体的信息不对称，农民很难及时获 得准确的需求信息和科学的分析指导, 在决策时的心理预 期往往具有盲目性、跟风性。大部分农民只能凭借经验和 不完整的信息碎片, 决定生产的品种和数量, 产销脱节现 象比较严重。例如, 农民在种植辣椒时往往依赖去年的价 格, 如果去年价格好, 农户会盲目扩大规模, 导致供大于 求, 价格暴跌; 而价格走低时又会一哄而散, 从而造成辣 椒价格的剧烈、频繁波动。

\section{3. 中国辣椒价格波动特征的实证分析}

\section{1. 研究数据}

由于中国辣椒的历史数据很难统计, 比较有权威的统 计资料文献, 例如中国统计年鉴和中国各地方政府统计年 鉴等, 都没有把辣椒产业统计进来, 很大程度上制约了辣 椒经济的统计研究。因此该研究对辣椒资料的搜集需综合 多方面信息并加工处理。本文通过对中国辣椒消费市场、 谷歌、百度网络查询与国际文献分析的方法搜集资料, 数 据主要来源于中国蔬菜网和中国辣椒网, 其中 2008 年5月 至2009年4月数据来源于中国蔬菜网日价格信息, 2009年5 月至2015年9月数据来源于中国辣椒网日价格公布信息, 经过处理之后共计为 89 个月度价格数据, 处理方法为月度 价格由每月的 5 号、 15 号、 25 号三日数据加总后平均计算 而来。另外，同时也对中国知名度较高的农产品批发市场 的辣椒价格进行了调查, 以作为参考或考证, 例如中国・北 京新发地、中国・山东寿光、中国・江苏金华、中国・深 圳布吉、中国・郑州等著名大型农产品批发市场。
的状态。另一方面, 随着更多地区调整农业产业结构, 不 断扩大辣椒种植面积, 加上辣椒种植成本（种子、农药、 化肥、用工费用等生产资料) 的不断增加, 自然灾害越来 越频繁等影响辣椒生产供给的因素越来越多, 造成了辣椒 产量的年度变化量忽高忽低, 导致价格很不稳定, 出现频 繁的大起大落。

\section{2. 计量统计方法}

辣椒价格的波动是由多方面因素引起的, 其波动的 特征也具有多样性, 很难用一种方法或模型对其波动的 不同特征进行统计研究。因此, 本文在对 2008 年 5 月至 2015年9月的辣椒价格时间序列数据进行研究时, 须借助 多种方法或模型来分析其波动的特征与规律：一是统计 描述法。该方法分析辣椒价格时间序列数据的集中、离 散趋势及分布形态, 揭示其代表性水平、离散型程度、 偏态与峰态程度特征; 二是X12季节调整法。该方法旨在 将辣椒价格的月度时间序列数据中的趋势、季节变化和 不规则变动分离出来, 分析其波动的趋势特征与规律; 三是BP滤波法。其是利用谱分析，把辣椒月度价格时间 序列看做互不相关的频率分量叠加, 通过研究各月度价 格变量的周期变化与频率域结构, 进而揭示辣椒波动的 周期性特征; 四是ARCH效应检验。该方法旨在分析辣椒 价格变动是否具有集簇性特征, 即一次大的辣椒价格波 动之后是否跟着另一个大的波动, 而在一次小的波动之 后会不会紧跟着一次小的波动的现象。

\section{3. 计量结果分析}

\section{3. 1. 辣椒价格波动的面上统计特征分析}

根据Eviews8.0软件统计显示, 中国辣椒价格变化呈 现出高频性、低水平性、较大离散性、轻微扁平和中等右 偏形态分布的特征。统计结果表2显示，2008年5月-2015 年9月 89 个月度辣椒价格时间序列数据的标准差为 1.83 , 表明辣椒价格的离散程度较大, 价格变化频繁且比较分散; 各月度价格的标准分数值 $|Z|<3.00$, 说明价格波动中 没有出现异常值, 辣椒价格虽出现多次大起大落, 但仍在 正常的波动范围之内; 在 $95 \%$ 置信水平下, 体现价格垂直 形态的峰度值为负且接近于 0 , 体现水平形态的偏度系数 为正且接近于 1 , 分别反映出 2008 年 5 月-2015年 9 月辣椒价 格呈轻微的扁平分布和中等的右偏分布特征, 一方面说明 
价格波动的幅度虽较大, 但仍是市场变化的正常表现; 另 一方面说明辣椒价格多在低价位运行, 其中价格较低的月 份占多数, 价格较高的月份占少数。

表2 89 个辣椒月度价格序列的统计指标描述。

\begin{tabular}{llllll}
\hline 指标 & 标准差 & 峰度 & 偏度 & 标准分数 $(|\mathrm{Z}|)$ & 置信度 \\
\hline 数值 & 1.83 & -0.13 & 0.81 & $<3.00$ & 0.95 \\
\hline
\end{tabular}

\section{3. 2. 辣椒价格波动的季节性分析}

文章采用X12季节调整法, 借助EVIEWS5.0对 2008 年5 月-2015年 9 月 89 个月度辣椒价格时间序列数据进行统计 处理, 分析价格波动的季节调整特征、季节因子特征、趋 势-循环特征和不规则要素特征。数据经季节调整后序列 特征如下图5-图8所示:

（1）多因素特征共同影响辣椒价格波动

季节性特征并非辣椒价格波动的唯一影响因素。图5 表示中国辣椒月度平均价格的季节调整序列变化情况。表 明在剔除季节调整影响后, 辣椒价格的波动主要包括趋势 循环要素和不规则要素（随机因子）, 即去除季节影响, 经季节调整之后, 辣椒价格的波动由趋势循环要素和不规 则要素决定。由突发性、随机性的偶然事件与循环趋势共 同作用下的辣椒价格波动趋势与图 7 和图 8 叠加效果有较 高的相似性。

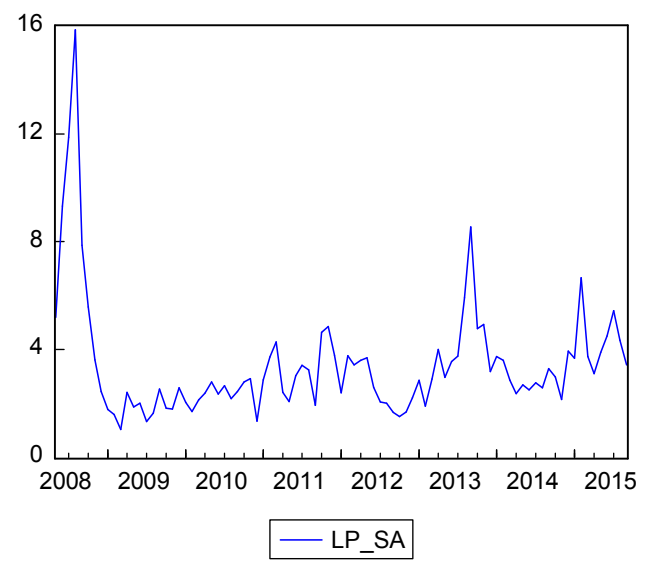

图5 季节调整引起的价格变化特征。

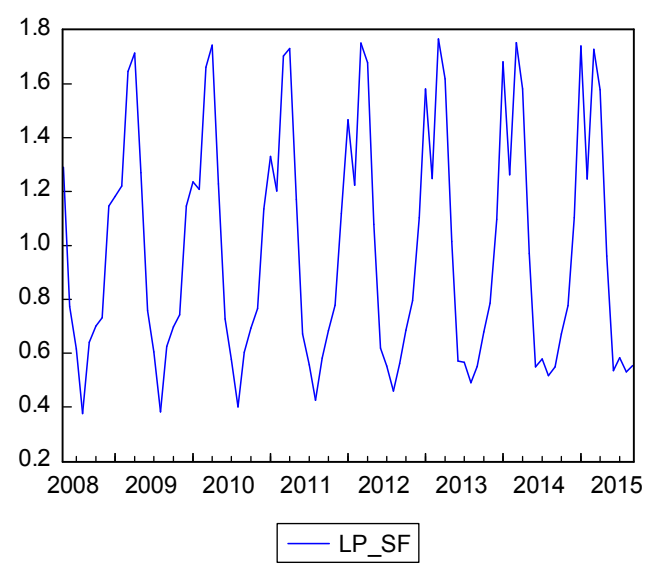

图6 辣椒价格的季节因子特征。

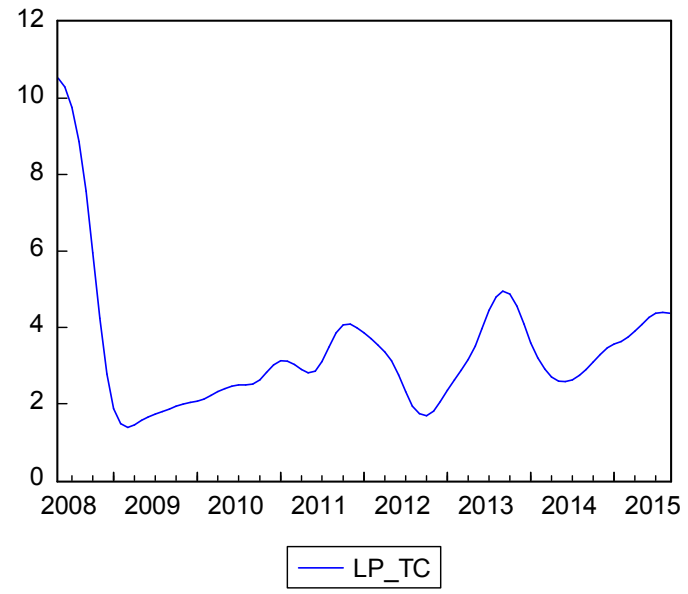

图7 循环趋势引起的价格波动。

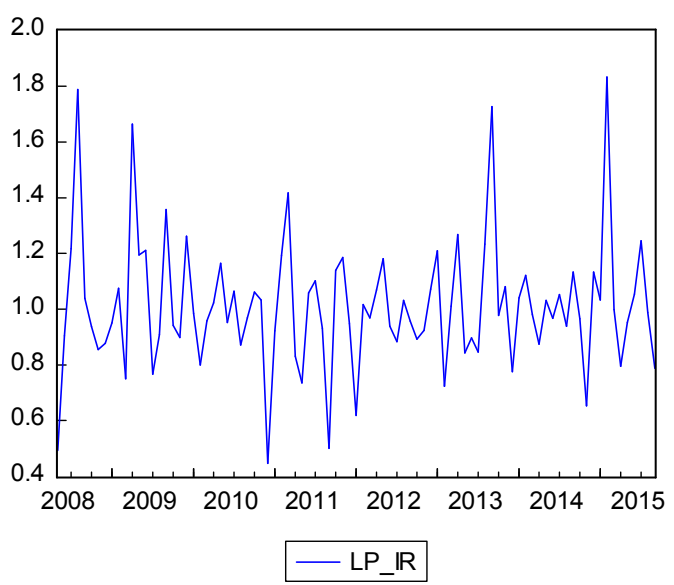

图8 不规则要素引起的辣椒月度价格波动。

（2）季节性特征对辣椒价格的影响

图6显示了中国辣椒价格在季节因子影响下的特征状 况。从图6可以看出辣椒价格波动具有较强的季节性变化 规律, 季节性影响周期大约持续一年, 从上一年的 8 月中 旬开始到下一年的 8 月中旬结束。辣椒价格在每年的第三 季度到下年的第一季度末受季节性正面影响下呈上升趋 势, 紧接着从下年第二季度初到第三季度末受季节性负面 影响下呈下降趋势, 该波动规律与辣椒种植和辣椒产品消 费规律相符合。

（3）循环趋势性特征对辣椒价格的影响

经过季节调整后, 图7显示了在循环与趋势特征共同 作用下的辣椒月度价格变化。在循环趋势的作用下, 2008 年5月至 2015 年 9 月辣椒价格出现了 3 个波动段的价格变化, 即2008年5月-2011年10月、2011年10月-2013年11月、 2013 年11月至今。

（4）不规则变动特征对辣椒价格的影响

图8显示了影响辣椒价格变化的不规则要素特征。其 对辣椒价格的影响是偶然发生的、随机性的、无规则可循 的, 主要包括突发性恶劣气候即时性政策公示、偶然性人 为预测失误、社会重大事件等。例如 2008 年美国次贷款危 机、中国 - 汶川地震、2010年中国 “辣翻天” 炒作疯涨事 件、2013年国际H7N9禽流感等突发事件, 均对辣椒价格的 波动造成了不同程度的影响。 


\section{3. 3. 辣椒价格波动的周期性分析}

季节调整后的循环趋势特征并不能说明辣椒价格变 动的周期性变化, 只有将趋势与循环特征分离出来, 才能

Fixed length symmetric (Baxter-King) filter

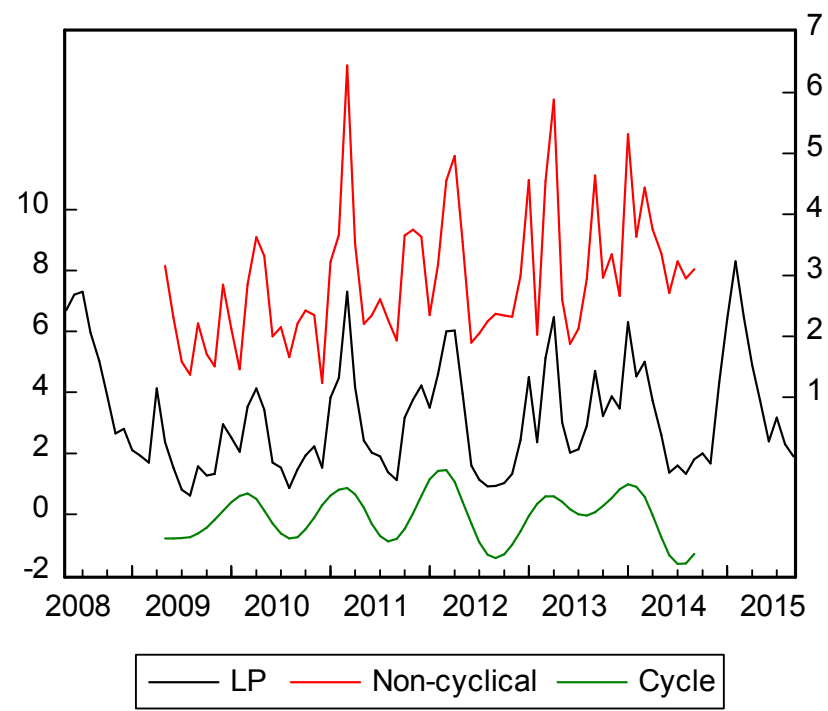

得到辣椒价格的周期性趋势。研究利用BP滤波法对辣椒价 格的循环趋势序列进行分解, 结果见下图9。

\section{Frequency Response Function}

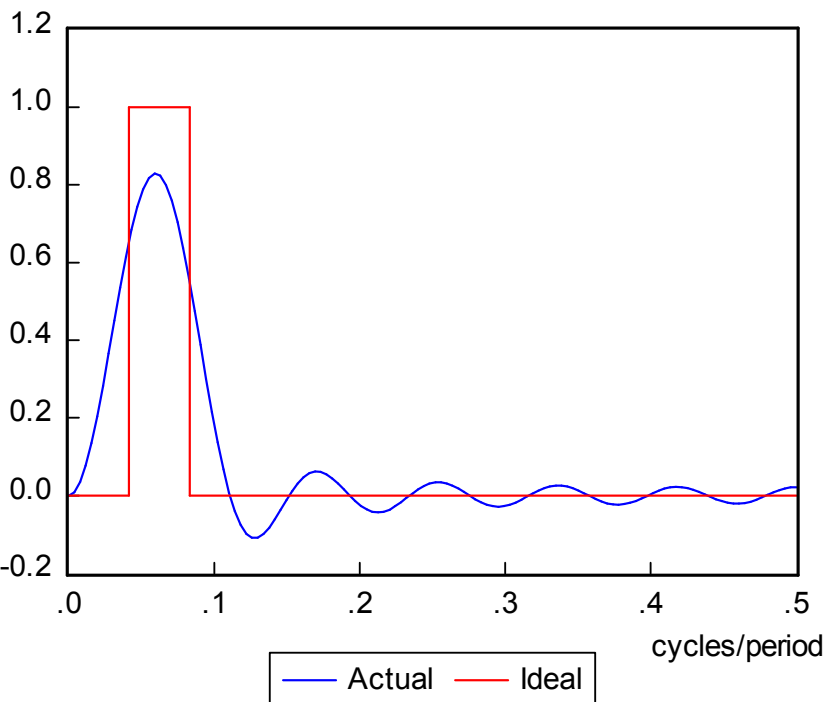

图9 中国辣椒价格的BP滤波分解。

图9左侧上半部分描述了辣椒价格波动的长期趋势序 列与非循环序列, 下半部分描述了周期循环序列。可知在 长期趋势下, 中国辣椒价格波动的周期性变化是必然的, 说明辣椒价格变化受自身行业社会经济规律的冲击作用 比较大。另外, 由右侧频率响应函数图的结果可以看出, 约 10 个月的权重最大, 说明中国辣椒价格存在 10 个月左右 的周期循环，据此中国2008年5月-2015年9月辣椒价格变 化可分为 7 个周期, 其中有 2 个不完整周期, 5 个完整波动 周期。

从5个完整周期来看, (1) 各周期跨度相差不大, 分 别为 10 个月、 10 个月、 10 个月、 9 个月、 9 个月, 每个周期 的持续时间基本一致，平均约为 10 个月。（2）从各周期 运行情况来看, 2008年以来, 中国辣椒价格波动的周期时 段比较稳定, 前两个周期上涨周期与下降周期存在一定程 度的对称性, 即每一完整波动周期的持续上涨时期与下降 时期差异较小; 但从第三完整周期的持续上涨期略小于下 降期, 第四、五完整周期的上涨期与下降期差异较大的角 度来看, 近年来持续上涨期与下降期的落差有越来越大的 趋势。（3）周期波动存在波峰愈来愈高, 波谷愈来愈低 的趋势, 说明近年来中国辣椒价格的波动愈来愈频繁且幅 度越来越大, 需要中国农业部市场监测机构特别关注这一 趋势。

\section{3. 4. 辣椒价格变化的集聚性分析}

根据国际农作物研究结果显示, 大蒜、大豆、蔗糖、 棉花等经济作物价格均表现出集簇性 (集聚性) 特征, 那 么辣椒是否也具备集族性特征呢?

根据表3显示, 研究可以通过对辣椒月度价格序列建 立滞后期为 2 的自回归均值模型: $1 \mathrm{p}_{\mathrm{t}}=\mathrm{C}+0.4101 \mathrm{p}_{\mathrm{t}}(-2)+\mathrm{u}$. 模型中的各检验指标均符合要求, 说明该模型是可靠的。
表3 自回归均值模型检验。

\begin{tabular}{lllll}
\hline 变量 & 系数 & 标准差 & T检验值 & P值 \\
\hline $\mathrm{C}$ & 1.784301 & 0.34522 & 5.168584 & 0.00000 \\
$\mathrm{LP}(-2)$ & 0.409769 & 0.093366 & 4.388862 & 0.00000 \\
判定系数 & 0.784747 & F检验值 & & 19.26211 \\
调整判断系数 & 0.775156 & $\mathrm{P}$ 值 & & 0.000033 \\
回归标准差 & 1.595103 & 奥克莱法则值 & 3.794473 \\
\hline
\end{tabular}

然后基于模型残差序列, 利用ARCH效应检验法对该特 征进行验证检验, 检验结果见下表4。ARCH效应检验显示, $\mathrm{F}$ 统计量与卡方统计量的概率P值均高于 0.05 , 反映出: 辣 椒价格的残差序列较小的波动集群部分中开始的小波动, 并没有紧跟较小的波动; 较大的波动集群部分中残差序列 一个大的波动后面也没有紧跟较大的波动。该检验结果表 明, 中国辣椒价格波动不存在ARCH效应即不具备集簇性特 征, 外部冲击虽然可以对辣椒价格波动产生一定的影响, 但其影响是有限的, 并不太明显。

表4 ARCH效应检验。

\begin{tabular}{llll}
\hline \multicolumn{3}{l}{ 残差序列的ARCH效应检验: } \\
\hline F统计量 & 1.424894 & $\mathrm{P}$ 值 & 0.179061 \\
卡方统计量 & 16.21271 & $\mathrm{P}$ 值 & 0.181687 \\
\hline
\end{tabular}

\section{4. 研究结论及对策}

\section{1. 研究结论}

在分析中国辣椒价格波动的现状与原因的基础上, 基 于描述性统计法、X12季节调整法、BP滤波、 $\mathrm{ARCH}$ 效应检 
验法等对中国 2008 年 5 月至 2015 年9月辣椒价格波动的特 征进行实证计量分析, 研究发现辣椒价格波动确实存在着 多重性特征：（1）辣椒价格变化呈现出高频性、低水平 性、较大离散性、轻微扁平和中等右偏形态分布的特征。

（2）辣椒价格波动具备较强的自然性的季节变化特征, 还显示出受社会经济变化影响的趋势一循环性规律特征, 同时还受外部偶然性因素影响而体现出的不规则性变化 特征。（3）辣椒价格变化有较稳定的周期性特征, 从5 个完整波动周期看，每个周期的持续时间基本一致，平均 约为 10 个月; 从各周期运行情况来看, 上涨周期与下降周 期存在一定程度的对称性, 但持续上涨期与下降期的落差 有越来越大的趋势; 另外, 周期波动存在波峰愈来愈高, 波谷愈来愈低的趋势。（4）辣椒价格波动不存在 $\mathrm{ARCH}$ 效 应, 这也是每次较明显的价格变化后, 价格波动的事态没 有继续扩大及影响期限较短的一个重要原因。

\section{2. 对策与建议}

中国是世界上重要农业大国, 除谷物粮食类之外, 许 多种特色农业经济作物在国际市场上也占据很大的份额。 事关农民收入与农业发展的特色农业经济作物价格的频 繁剧烈波动会损害生产者和消费者的利益, 不利于产业和 相关产业现代化的发展, 也会影响国际市场的发展。建议 中国政府应该结合特色农业经济作物价格变化的原因, 认 真把握价格变化的规律特征, 促进特色农业产业市场的健 康发展。 扶植。

第一，加强政府对特色农业经济作物主产区的支持与

根据长期价格数据来看, 特色农业经济作物辣椒价格 变化具有轻微扁平和中等右偏形态分布的特征即辣椒价 格多在低水平运行, 应加大对中国 (河南、湖南、四川等) 经济作物主产区的政策支持, 对其进行适当补贴, 增加种 植户收入，提高农户的积极性。同时，加大技术投入，进 一步提高特色农经产品的标准、品牌化程度, 提高其产品 的附加值。

第二, 加强特色农业经济作物价格信息平台建设, 加 强市场监管。

针对特色农业经济作物（例辣椒）价格变化的频繁性 且幅度越来越大的趋势特征, 中国政府应积极规避信息的 不对称, 整合产业信息, 加强产业价格信息平台建设及做 好信息监测与预警。同时特色农业经济作物隶属小宗农产 品, 政府很难把握政策干预的力度 (小额农产品的政策干 预极易可能引起市场的巨大波动），加上易受资金操控和 炒作，应该加强市场监管，提高违法成本，打击圈积居奇 等投机炒作现象。

第三，做好市场淡旺季的供需调整，大力发展中国特 色农业经济作物产品期货。

特色农业经济作物（例辣椒）价格变化存在季节性、 周期性和趋势循环性特征, 掌控其价格变动的未来趋势, 合理调整淡旺季供给差异, 有利于实现市场的供求平衡。 另外培育与发展特色农产品期货, 也是防止价格频繁波动 的重要手段。公开透明的期货市场价格信号有助于指导农
民的生产种植, 减少中间流通成本, 既能保证农民的正常 收入增长, 也可以更好地平缓价格波动。

第四, 提高政府公关危机的处理能力, 沉着应对突发 风险。

特色农业经济作物价格变化具有不规则性特征, 容易 受突发性、随机性、偶然事件的影响, 例如地震、旱涝、 非典、H7N9、蒜你狠、辣翻天、金融危机等自然与社会风 险事件。中国政府应加强对偶然性风险事件的监测与追踪, 建立相应的农产品公关危机处理机制, 消除或减轻不规则 风险因素对特色农业经济作物（例如辣椒）价格波动的影 响。另外, 针对经济作物价格波动的是或非集簇性特征, 若出现较大幅度的价格变动, 事后不易惊慌; 出现较小的 价格波动后, 也要时刻保持警惕。

第五，做好特色农业经济作物相关的信息统计，把握 国际市场走势。

目前中国官方权威统计年鉴中还没有辣椒、大蒜等小 宗农产品的信息统计, 中国政府可以尝试扩大统计的宏观 性内容, 以便于把握小宗农产品市场。另外, 认真考虑国 际进出口贸易因素, 把握国际市场趋势, 在保障中国市场 需求的前提下, 合理控制特色农业经济作物进出口规模, 这也是防止价格大起大落所必须注意的关键因素。

\section{致谢}

首先感谢2016农业科学与生物技术国际会议组委会 及专家对该研究成果的认可; 其次感谢中国2014年社科基 金重点项目 (13AGL004) 和中国2015年河南省教育厅人文 社科项目 (2015-QN-198) 的鼎力资助; 最后感谢中国・周 口师范学院 (周口发展研究中心) 提供的技术支撑。

\section{参考文献}

[1] 朱信凯等. 信息与农产品价格波动: 基于EGARCH模型的分析 [J].管理世界，2012(11)。

［2］宋雨河. 农户生产决策与农产品价格波动研究一一以果类 蔬菜为例 [D]. 中国农业大学, 2015:79-98。

[3] 李正辉, 路芸, 何融. 农产品价格周期性波动研究一一基于 小波分析 [J]. 调研世界, 2013。

[4] 夏冰. 农产品价格波动聚集特征验证及趋势预测 [J]. 统计 与决策, 2015。

[5] 周金城. 中国农产品价格波动的非线性动态调整研究 [D]. 湖南大学, 2014:107-115。

[6] 宋雨河, 武拉平. 价格对农户蔬菜种植决策的影响 [J]. 中国 农业大学学报(社会科学版). 2014 (02)。

[7] 庄岩. 中国农产品价格波动的影响因素及政府调控研究 [D]. 哈尔滨商业大学, 2013:57-718。

[8] 付莲莲. 国内农产品价格波动影响因素的结构及动态演变 机制 [D]. 南昌大学, 2014: 122-138。 
[9] 文春玲. 中国农产品比价形成及其变动规律研究 [D].中国 农业大学, 2014:86-102。

[10] 姜雅莉. 蔬菜价格波动及传导研究 [D]. 西北农林科技大 学, 2013:112-118。

[11] 蒋兴红. 农产品国际贸易对中国经济增长的影响研究 [D]. 西北农林科技大学, 2014:67-80。

[12] 董志伟. 理顺工农产品比价与调控通货膨胀的矛盾与协调 [D]. 对外经济贸易大学, 2014:32-48。

[13］庞贞燕等. 期货市场能够稳定农产品价格波动吗 [J]. 金融 研究, 2013：36-42。

[14] 方燕, 邓洁. 大豆期现货与豆油豆粕价格传导关系的实证研 究 $[J]$. 价格理论与实践, $2013(04)$ 。

[15] 谢长伟. 农户与农产品期货市场对接模式研究 [D]. 河南农 业大学, 2013:71-98。

[16] 董婉璐等. 美国农业保险和农产品期货对农民收入的保障 作用 [J]中国农村经济, 2014(9)。

[17] 郑高强等. 中国特色农业现代化道路模式的选择 [J]. 农业 现代化研究, 2008（4）:390-394。

[18] 张辰利. 中国棉花价格指数波动特征分析 $[J]$. 农业技术经 济, 2013(9) : 42-50。

[19] 黎东升. 中国生猪价格波动新特征--基于HP和BP滤波法的 实证分析 $[J]$. 农村经济, 2015（6）:21-24。

[20］韩雯. ARIMA模型在贵州省农产品价格预测中的应用--以辣 椒为例 [J]. 安徽农业科学, 2011 (21) : 26-30。

[21] 张建华. 基于小波神经网络的辣椒价格时间序列预测模型 [J]. 中国食物与营养, 2014（12）：46-50。

[22] 赵安平. 北京市批发市场蔬菜价格引导关系研究 [J]. 中国 农学通报, 2014（12）：46-50。

[23] 王永平等. 中国辣椒产业发展现状及趋势 [J]. 河北农业科 学, 2009 (6) : 135-138。
[24] 马艳青. 中国辣椒产业形势分析 [J]. 辣椒杂志, 2011 (1) $: 36-40$ 。

[25] 李晴. 世界辣椒产业现状与发展趋势 $[\mathrm{J}]$. 湖北农业科 学, 2009 (9) : 9-13。

[26] Futures Prices in Supply Analysis: Are Instrumental Variables Necessary? Nathan P. Hendricks American Journal of Agricultural Economics, Volume 97, Issue 1, 2015, Pages 25.

[27] The Behavior of Bid-Ask Spreads in the Electronically -Traded Corn Futures Market, Philip Garcia; ScottH. Irwin. American Journal of Agricultural Economics, Volume 96, Issue 2, 2014, Pages 527-577.

[28] The Role of Index Trading in Price Formation in the Grainsand 0il seeds Markets, Christopher L. Gilber JOURNAL OF AGRICULTURAL ECONOMICS, Volume 65, Issue 2, 2014, Pages 303-322.

[29] Impact of Cost Shockson Consumer Prices in Vertically -Related Market FrenchS of Drink Market, Céline Bonne, American Journal of Agricultural Economics, Volume 95, Issue 5, 2013, Pages 1001-1108.

[30] Understanding International Trade in Agricultural Products, Tim Josling; Kym Anderson, American Journal of Agricultural Economics, Volume 92, Issue 2, 2010, Pages 412-446.

[31] The pepper patatin- like phospho lipase Ca PL functions in plant cell death and defense signaling; Dae Sung Kim; Plant Molecular Biology, Volume 84, Issue 3, 2014, Pages 303-344.

[32] Production of the Pepper Aroma Compound, Aerialxi dation of aiene - Cheng Huang, Journal of Agricultural and Food Chemistry, Volume 62, Issue 44, 2014, Pages 109-115. 